\title{
OPINIÃO DE ESTUDANTES UNIVERSITÁRIOS SOBRE A EDUCAÇÃO A DISTÂNCIA (EaD), NO CONTEXTO DAS CIÊNCIAS FARMACÊUTICAS
}

\author{
OPINION OF UNIVERSITY STUDENTS ON THE DISTANCE \\ EDUCATION IN THE CONTEXT OF \\ PHARMACEUTICAL SCIENCES
}

\author{
Aníbal de Freitas Santos Júnior ${ }^{1}$ \\ Hildonice de Souza Batista ${ }^{2}$
}

\begin{abstract}
Resumo
Este artigo tem como objetivo discutir a inserção da Educação a Distância (EaD) na prática das Ciências Farmacêuticas. A população de estudo constou de 200 indivíduos (estudantes universitários), na cidade de Salvador/Bahia. Para análise dos dados, foram utilizadas as respostas a um questionário semiestruturado, no qual os estudantes entrevistados expressaram sua opinião a respeito da $\mathrm{EaD}$ no Curso de Farmácia. Os estudantes informaram o uso da Internet como ferramenta de auxílio nas pesquisas e nos trabalhos acadêmicos, além de outras finalidades alternativas, como a interação em tempo real, através de chats e comunidades virtuais. A maioria $(n=179)$ respondeu que acreditava ser passiva a interatividade entre o usuário e o ambiente $\mathrm{EaD}$, sendo o Moodle o principal ambiente virtual de aprendizagem. Conveniências de horários, atenção individualizada, curso no prazo prometido e qualidade de materiais didáticos figuraram entre os principais atrativos para um curso a distância. Entre as principais desvantagens citadas pelos entrevistados, evidenciaram-se: a exclusão digital (relacionada à necessidade de computadores); o grande número de estudantes por tutor; o uso excessivo de questões de múltipla escolha; e o não cumprimento das atividades pelos estudantes (desistências). A maioria dos entrevistados julgou importantes as tecnologias da informação e comunicação (TIC) como apoio ao ensino presencial nos cursos de Ciências Farmacêuticas e, para a formação profissional, os níveis de capacitação: técnica, atualização e graduação. As disciplinas de maior abordagem teórica foram citadas como as que mais se enquadravam ao longo de um curso a distância, em Farmácia. Os entrevistados demonstraram-se conscientes da necessidade da Educação a Distância em sua formação, porém, preocupados com o nível de qualidade e complementaridade dos estudos, por conta da especificidade de cada atividade prática que envolve o profissional de farmácia e o paciente.
\end{abstract}

Palavras-chave: Educação a distância. Estudantes. Tecnologia da informação e comunicação.

\begin{abstract}
This article aims to discuss the inclusion of distance education in the practice of Pharmaceutical Sciences. The study population consisted of 200 individuals (students) in the city of Salvador / Bahia. For data analysis, were used in semi-structured questionnaires, in which students interviewed expressed their opinions about distance education, in the course of Pharmacy. Students highlighted the use of the Internet as a tool to aid in research and scholarship, as well as other alternative

\footnotetext{
${ }^{1}$ Professor Adjunto da Universidade do Estado da Bahia (UNEB), Departamento de Ciências da Vida (DCV). Email: afjunior@uneb.br - Salvador,BA, Brasil.

${ }^{2}$ Professora Orientadora do Curso de Especialização em Educação a Distância, da Universidade Aberta do Brasil. E-mail: hildonice@ gmail.com - Salvador, BA, Brasil.
}

Recebido em: 30/05/2011 / Aprovado em: 10/02/2012.

\begin{tabular}{l|l|l|l|l|l|l|} 
(C) ETD-Educ. temat. digit. & Campinas, SP & v.14 & n.2 & p.258-274 & jul./dez. 2012 & ISSN 1676-2592 \\
\hline
\end{tabular}


purposes, such as real-time interaction, through chat rooms and virtual communities. The students reported the use of the Internet as a tool to aid in research and school work and other purposes alternatives such as real-time interaction through chat rooms and virtual communities. Most students $(n=179)$ responded that he believed to be passive interactivity between the user and the environment distance education, and Moodle, the leading virtual learning environment. Convenient schedules, individual attention, progress in the promised time and quality of teaching materials, were among the main attractions for a distance learning course. Among the main disadvantages cited by respondents, showed up: the digital divide (related to the need for computers), the large number of students per tutor, the excessive use of multiple choice questions and the failure of activities for students (dropouts). Most respondents judged important information technology and communication (ICT) to support the classroom teaching the courses of Pharmaceutical Sciences, and for vocational training, skill levels: technical, update and graduation. The disciplines of greater theoretical approach were cited as those most fit over a distance course in Pharmacy. With the analysis of such data, it was found that respondents showed an awareness of the need for distance education in its formation. However, had expressed concern about the quality and complementarity of the studies, due to the specificity of each activity that involves the professional practice of pharmacy and the patient.

Keywords: Distance education. Students. Information technology and communication.

\section{INTRODUÇÃO}

O crescimento tecnológico proporcionou uma ampla diversidade de técnicas e recursos científicos e acadêmicos. Com isso, houve uma revolução dos modos de produção, comercialização e educação, levando a mudanças no paradigma educacional. Tal centro (educação) tornou-se um campo de investigação muito complexo, principalmente no que tange aos recursos de transmissão do conhecimento. A Internet trouxe mudanças significativas na área de saúde, e nesse contexto se inserem as Ciências Farmacêuticas.

Iniciada, provavelmente, a partir de aulas por correspondência que iam desde cursos de escrita jornalística a aulas de mecânica, a Educação a Distância (EaD) tornou-se uma modalidade educativa praticada em todo o mundo. Brasil, Cuba, Estados Unidos, Canadá, Austrália, China, Índia, Indonésia, Japão, Nova Zelândia, Rússia, Portugal (criação da Universidade Aberta, 1988), Espanha, Venezuela, Costa Rica, Inglaterra, dentre outros, modificaram a oferta de cursos na modalidade a distância, com o advento das tecnologias digitais (CASTRO; NUNES, 1996).

Combinação de flexibilidade, liberdade, crítica e democratização, e a utilização simultânea de meios de comunicação, técnicas de ensino, metodologias de aprendizagem, dentre outros aspectos, caracterizam a EaD.

Conforme exposto, a implantação e o aperfeiçoamento de uma geração nova de sistemas, por meio das Tecnologias de Informação e Comunicação (TIC), ampliaram a EaD

\begin{tabular}{l|l|l|l|l|l|l|} 
(C) ETD-Educ. temat. digit. & Campinas, SP & v.14 & n.2 & p.258-274 & jul./dez. 2012 & ISSN 1676-2592 \\
\hline
\end{tabular}


no mundo e no Brasil, promovendo oportunidade educacional para distintos grupos humanos em diversas áreas do conhecimento e em diferentes localidades, não somente nos aspectos quantitativos, mas também nos qualitativos (PÉREZ JUSTE, 1998).

A Educação a Distância $(\mathrm{EaD})$ foi legalmente implantada no Brasil pela Lei de Diretrizes e Bases da Educação Nacional, no 9.394, de 20 de dezembro de 1996 e regulamentada pelo Decreto $\mathrm{n}^{\circ} 5.622$, de 20 de dezembro de 2005, que estabelece regras para a EAD na Educação Básica, Superior e Profissional (BRASIL, 1996; BRASIL, 2005).

Segundo a Associação Brasileira de Ensino a Distância (ABED), algumas vantagens são atribuídas à EAD: maior flexibilidade em relação a horários e lugares, menor custo para o estudante e maior inclusão social (ABED, 2007) - parâmetros, muitas vezes, suprimidos, na maior parte da sociedade, devido ao ritmo acelerado da vida, que é imposto pelo sistema neoliberal (valorização do lucro e da produtividade), gerando maior individualismo e isolamento da população desfavorecida cultural, social e economicamente.

A busca contínua pelo aperfeiçoamento da qualidade da comunicação faz do ser humano um veículo de disseminação do conhecimento. Levi (1998) propõe uma análise da evolução da comunicação no mundo contemporâneo, agregando valores aos momentos culturais, desde as épocas pré-históricas até os dias atuais; sugere o termo "mutação antropológica”, envolvendo as diásporas até a Revolução Industrial e seu impacto sobre a sociedade e a comunicação.

Alves e Nova (2003) definem a EaD como uma das modalidades de ensinoaprendizagem, facilitada pela mediação dos suportes tecnológicos digitais e de rede, seja esta inserida em sistemas de ensinos presenciais, mistos ou completamente realizada por meio da distância física. Nesse contexto, a EaD constitui-se em um processo multifacetado e complexo, no qual o estudante tem maior autonomia para encontrar mediação pedagógica mais adequada ao seu aprendizado. Essa mediação pedagógica pode ser realizada de modo articulado com as mídias, os materiais impressos, as teleaulas, as videoconferências, as teleconferências, o CD-ROM ou a Internet. Portanto, a necessidade de interatividade, interação, organização e planejamento torna essa metodologia de ensino algo surpreendente, e se faz necessário discutir sua inserção no âmbito mundial, nacional e local, destacando suas vantagens e desvantagens.

Echeita e Martin (1995, p. 37) defendem que a interação deve ser considerada como núcleo da atividade do processo ensino-aprendizagem em EaD, uma vez que o conhecimento 
passa a ser construído coletivamente, isto é, passa a ser co-construído, justamente porque há interatividade entre duas ou mais pessoas que participam dessa atividade.

Fagundes et al. (1999) discutem a importância do desenvolvimento de novas habilidades ou talentos na EaD, a exemplo da capacidade de resolver problemas por intermédio dos três ' $C$ ': comunicação, colaboração e criatividade; da aprendizagem e da postura cooperativa na Internet; e da estrutura de funcionamento de um ambiente em rede e heterárquico. Por conseguinte, a necessidade de familiarização com tecnologias da informação e comunicação (TIC) é o ponto-chave para a disseminação do conhecimento.

A inserção da $\mathrm{EaD}$ na área de Saúde é algo real, necessário e desafiante. É uma tentativa sistemática de facilitar mudanças na prática clínica, devendo, assim, deixar seu enfoque meramente instrucional, para estar mais voltada à facilitação do aprendizado (CHRISTANTE et al., 2003).

Corroborando esse pensamento, Tomaz e Van Der Molen (2011) avaliaram a aceitabilidade de um curso, na modalidade $\mathrm{EaD}$, entre os profissionais que atuavam no Programa Saúde da Família (PSF), no Estado do Ceará/Brasil, com o objetivo de criar novas estratégias para prover Atenção Primária à Saúde da população brasileira. Em seus resultados, os autores evidenciaram que a maioria dos participantes do estudo não tinha experiência prévia com a EaD, porém, o resultado da avaliação indicou que a participação no planejamento das atividades, a motivação e a disponibilidade são exemplos de variáveis que mostraram que a $\mathrm{EaD}$ pode ser uma estratégia adequada à educação permanente dos profissionais de Saúde da Família.

Portanto, a diversificação das técnicas de produção de medicamentos e de softwares de programação logística e operacional, de forma rápida e intensa, disseminou a inserção da transmissão de conhecimento a distância na prática da saúde. Nesse cenário, encontram-se as teleconferências, a telemedicina, os sistemas de reprodução e as técnicas de monitoramento da qualidade de formas farmacêuticas on-line. Paralelamente a esse cenário, há a intensificação do processo produtivo e da competição mercadológica, gerando novas teorias, processos, modelos e a necessidade de adequação dos componentes curriculares dos cursos de Farmácia, em todo o Brasil e no mundo.

Gomes e Lopes (2006) propõem uma reflexão sobre a prática da $\mathrm{EaD}$ e do ambiente de aprendizagem on-line, quando asseveram que as perspectivas da $\mathrm{EaD}$ são inúmeras e das mais favoráveis no contexto do processo ensino-aprendizagem. Isso é nitidamente visualizado nos artigos publicados em periódicos de diversas áreas, na implementação da Telemedicina,

\begin{tabular}{l|l|l|l|l|l|l} 
(C) ETD-Educ. temat. digit. & Campinas, SP & v.14 & n.2 & p.258-274 & jul./dez. 2012 & ISSN 1676-2592 \\
\hline
\end{tabular}


nos ambientes virtuais e nos fóruns de discussão. Portanto, o processo multifacetado e complexo que é a EaD constitui-se como uma ferramenta muito importante na prática da educação contemporânea. Em concordância, Souza, Silva e Araújo (2011) discutem a importância do exercício da autoria em ambiente virtual e afirmam que as ferramentas digitais e os ambientes colaborativos de aprendizagem possibilitam a alunos e professores a oportunidade de (re) construir, individual ou coletivamente, sua autoria e produzir seus textos, vídeos e artefatos quaisquer.

Segundo Litto (2009), o Brasil agora está tomando seu devido lugar entre os países que fazem amplo uso da EaD para dar acesso ao conhecimento e à certificação de competências a camadas cada vez maiores da população. Todavia, a EaD necessita de maior divulgação, organização e credibilidade por parte dos poderes públicos, pois, como afirma o autor, no seu texto: "a educação a distância não tem a finalidade de competir com a presencial e sim oferecer uma opção de boa qualidade para quem não tem acesso à educação convencional".

O sistema de educação do Brasil e da Bahia vem sofrendo uma metamorfose no que se refere às alternativas de ensino, lincados ou não ao virtual. Em contexto global, Gonzalez, Pohlmann Filho e Borges (2001) fazem um comparativo da inserção da informação digital no ensino presencial e EaD. Atualmente, o uso da Internet e a transmissão a cabo de informações podem ser associados ao ensino das Ciências Farmacêuticas, como, por exemplo, na produção em linha de medicamentos, na notificação de eventos adversos e na área acadêmica. Ainda, destacam-se as vantagens de ampliação conhecimentos e oportunidades de acesso à educação, propiciando um processo de maior inclusão social e digital, através da participação em palestras on-line, videoconferências e outros eventos que discutem a Saúde, na prática da equipe multiprofissional. Portanto, o uso das TIC proporciona a disseminação do conhecimento, em concordância com alguns princípios do processo ensino-aprendizagem virtual (cooperação, colaboração e interação).

O crescente número de usuários de Internet desencadeou um aumento na busca dos serviços de farmácias virtuais brasileiras. A farmácia virtual é um sistema informatizado com funções potenciais de uma farmácia real e permite transações comerciais por meio remoto, sem proximidade física entre o comprador e o vendedor de medicamentos (GONDIN; FALCÃO, 2007). Portanto, discutir a inserção do farmacêutico e seus princípios éticos se torna extremamente relevante na condução do uso de medicamentos obtidos on-line.

\begin{tabular}{l|l|l|l|l|l|l} 
(C) ETD-Educ. temat. digit. & Campinas, SP & v.14 & n.2 & p.258-274 & jul./dez. 2012 & ISSN 1676-2592 \\
\hline
\end{tabular}


Nesse contexto também se enquadram as Ciências Farmacêuticas, cujo processo de ensino-aprendizagem e cujos atores da educação (escola-estudante-professor) tradicional, presencial, estão se inserindo no âmbito da Educação a Distância $(\mathrm{EaD})$. Este artigo tem como objetivo discutir a inserção da EaD na prática das Ciências Farmacêuticas, através de uma visão crítica dos estudantes de graduação, no que se refere à organização e à disseminação do conhecimento em $\mathrm{EaD}$, na área farmacêutica.

\section{MÉTODO}

A pesquisa teve como desenho de estudo um modelo observacional de corte transversal descritivo. Foi realizada uma revisão bibliográfica dos artigos publicados sobre a $\mathrm{EaD}$ e a área de saúde em livros, revistas e periódicos. Este estudo foi realizado em três Instituições de Ensino Superior (IES), na cidade de Salvador - Bahia, uma instituição privada e duas públicas. As IES foram selecionadas de modo a permitir uma análise mais precisa da opinião dos estudantes sobre $\mathrm{EaD}$ no ensino de Ciências Farmacêuticas.

A população de estudo constou de 200 indivíduos do sexo masculino e feminino, com idade entre 18 e 50 anos, matriculados nas IES (em nível de graduação), que aceitaram participar do estudo por meio de respostas ao questionário semiestruturado, cedido pelo pesquisador, com o objetivo de verificar a opinião dos usuários sobre a $\mathrm{EaD}$. A seleção dos participantes foi feita de forma aleatória, ou seja, foram entrevistados aqueles que estiveram presentes nos dias da coleta de dados, caracterizando uma amostragem intencional não representativa de 200 indivíduos no total, envolvendo as três IES. A fonte de dados para obtenção dos resultados foi do tipo primária.

Os entrevistados foram abordados ao chegar ou sair das salas de aulas, após autorização da coordenação e dos professores da IES. Foi apresentado o termo de consentimento livre e esclarecido, que foi assinado pelos entrevistados. O estudo contou com apenas um encontro com cada entrevistado, tempo suficiente para a coleta das informações. A coleta dos dados foi realizada no período de maio a junho de 2010, após aprovação (Parecer 1869/2010) do Comitê de Ética em Pesquisa de uma IES, em Salvador/Ba. Esse trabalho foi pautado na Resolução 196/96 do Conselho Nacional de Saúde (CNS). Os questionários foram analisados separadamente, para fazer a construção dos resultados. Os programas de informática utilizados foram Microsoft Office Excel como programa estatístico, para a realização dos gráficos e tabelas, e Microsoft Office Word, para digitação.

\begin{tabular}{l|l|l|l|l|l|l|} 
(C) ETD-Educ. temat. digit. & Campinas, SP & v.14 & n.2 & p.258-274 & jul./dez. 2012 & ISSN 1676-2592 \\
\hline
\end{tabular}




\section{RESULTADOS E DISCUSSÕES}

A ampla necessidade de aperfeiçoamento do farmacêutico fez com que este buscasse informações em diversas fontes. A expansão das formas de disseminar conhecimentos foi rápida e intensa, cabendo a esse profissional consultar fontes de diversas etiologias, inclusive aquelas contidas no mundo virtual. Nesse contexto, a percepção da temática pelos usuários (entrevistados) foi relevante, uma vez que as necessidades, as prioridades, as aspirações e as atitudes nortearam as opiniões dos acadêmicos, o que influi direta ou indiretamente no acesso aos recursos de aprendizagem, sejam eles presenciais ou virtuais.

Foram entrevistados 126 estudantes do sexo feminino e 74 do sexo masculino, na faixa etária de 20 a 50 anos (maior predominância de 20 a 30 anos). Tal predominância do sexo feminino não implica em uma variável significativa da análise deste trabalho, uma vez que o objetivo foi avaliar a opinião de estudantes universitários sobre a $\mathrm{EaD}$, no contexto do ensino das Ciências Farmacêuticas, em Salvador/BA. Ao analisar a questão socioeconômica, verificou-se que 103 possuem vínculo empregatício, com faixa de renda predominante entre $\mathrm{R} \$ 1.000,00$ a $\mathrm{R} \$ 2.500,00$. A maioria dessas atividades inclui estágios e prestação de serviços em shoppings, telemarketing, entre outras.

Questionados sobre o tempo disponível semanal para atividades acadêmicas, 81 entrevistados revelaram dispor de até 4 horas para estudo, enquanto que 73 dispunham de 4 a 10 horas semanais para a realização de suas atividades estudantis. Tal fato permite inferir que, devido às diversas atividades que cada estudante executa, há pouco tempo destinado para os estudos.

Dos entrevistados, 193 destacaram o uso da Internet como ferramenta de auxílio nas pesquisas e nos trabalhos acadêmicos. Questionados sobre o tempo de acesso, a maioria informou que usa a web diariamente (Gráfico 1). Destes, 101 usam a conexão banda larga; 26, a discada; e 73, cablemodem. Sobre o sistema operacional utilizado, 171 usavam o Windows e 29, o Linux. Dos usuários de Internet, 179 usavam o Internet Explorer como navegador de Internet e 21, o Mozilla Firefox. 


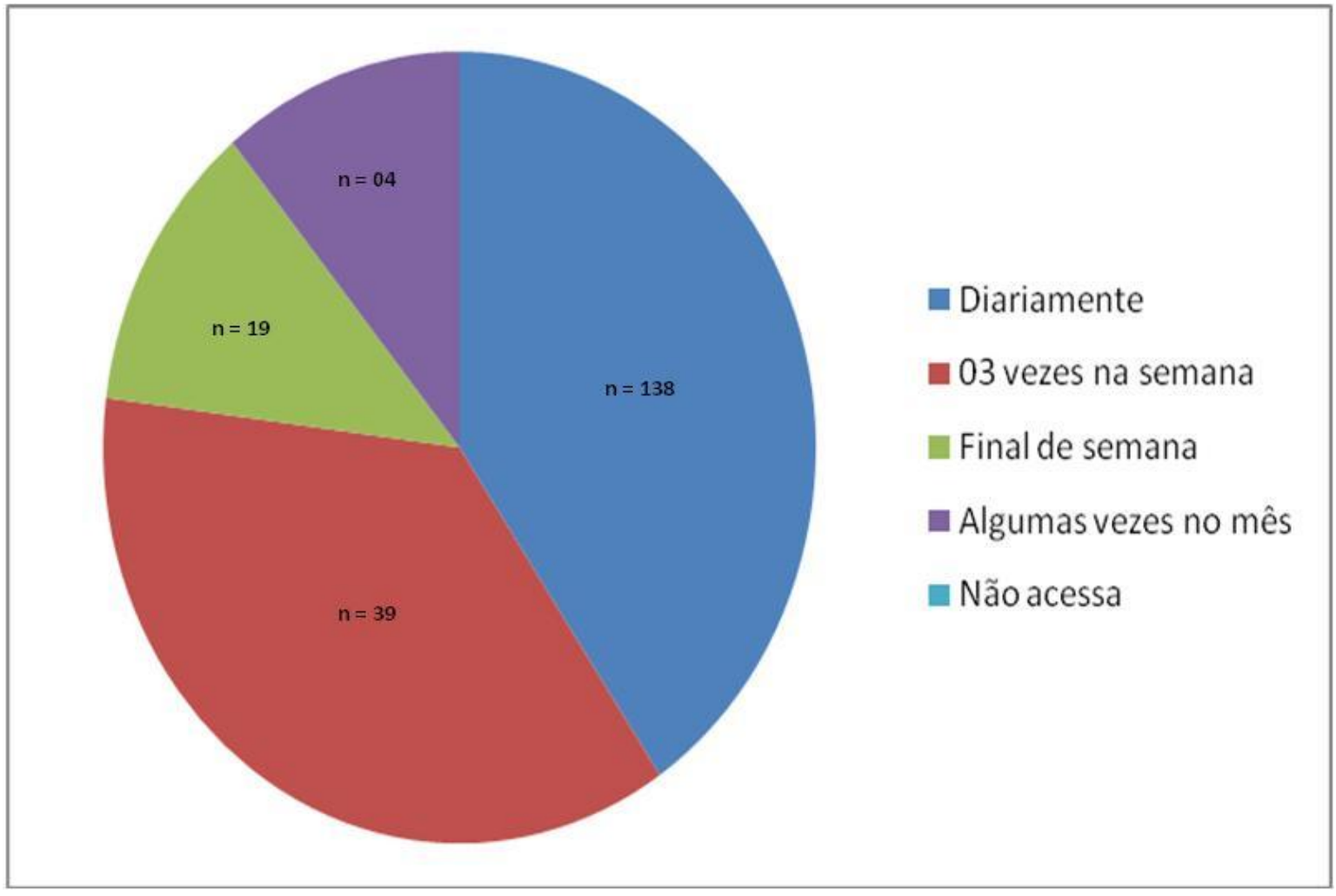

GRÁFICO 1 - Frequência de uso da Internet pelos entrevistados $(n=200)^{3}$

Questionados sobre o local de uso da Internet, os entrevistados revelaram que a residência e a Faculdade são os sítios mais utilizados. Afinal, são os locais em que os estudantes permanecem por mais tempo. Os entrevistados informaram que os principais programas de comunicação para os estudos são o e-mail, o Orkut e o Msn Messenger (Gráfico2). Acredita-se que estes programas foram mais relacionados devido à faixa etária da maioria dos entrevistados, que destinam parte do tempo a rede sociais, ou seja, a comunidades virtuais e bate-papo on-line.

\footnotetext{
${ }^{3}$ FONTE - Pesquisa de Campo, 2011, sendo a mesma dos demais grque aparecem neste trabalho.
} 


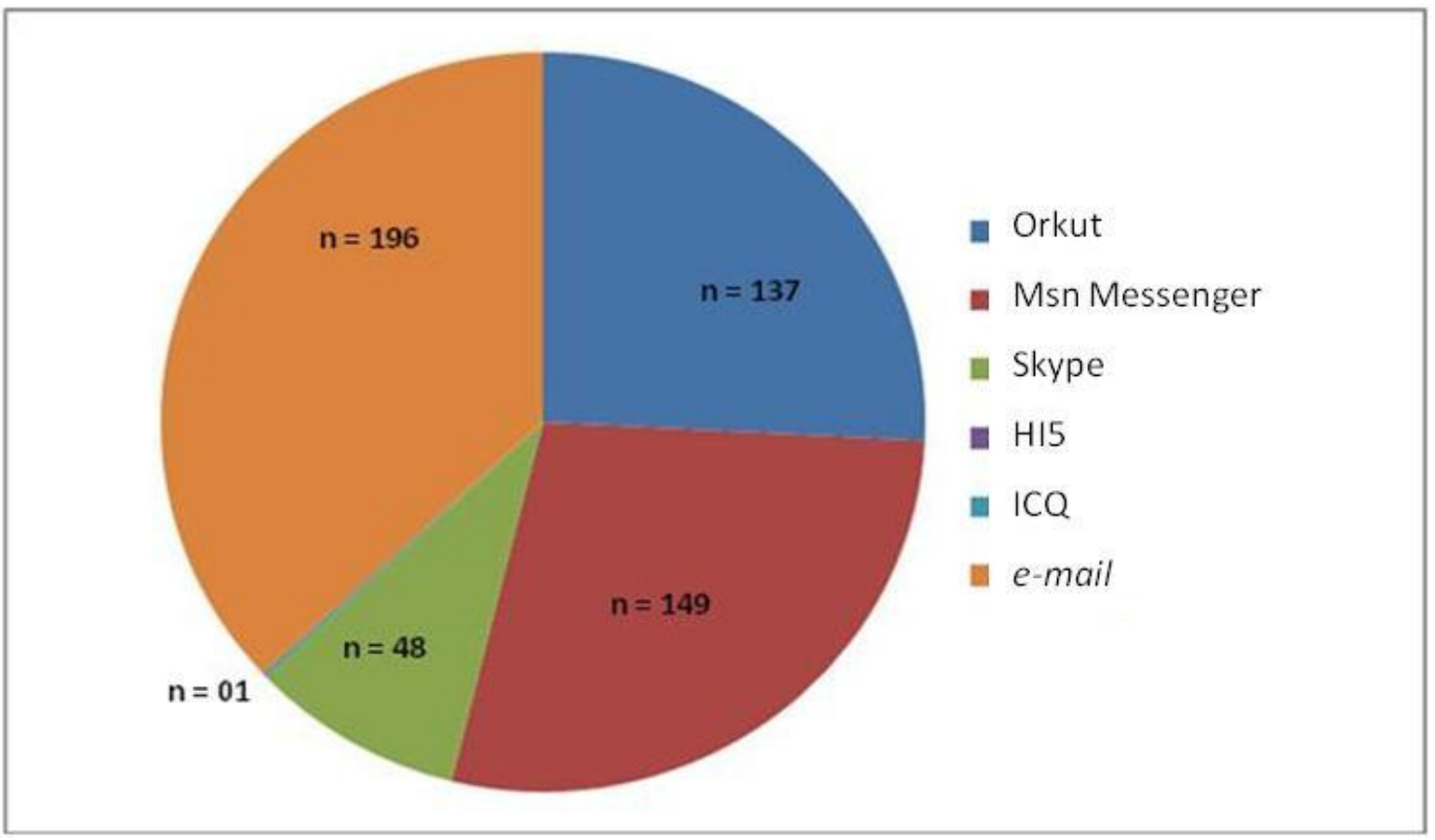

GRÁFICO 2 - Programas de Comunicação usados pelos entrevistados

Ainda, perguntados sobre a finalidade do uso da Internet, os entrevistados destacaram como fins principais o envio e o recebimento de e-mails, a participação em comunidades de relacionamento, a interação em tempo real e a busca de conteúdo para aulas. Com a disposição de material na web, hoje, fica mais fácil complementar os estudos por meio de materiais extras, obtidos on-line. Essa facilidade de busca da informação atrai o estudante, uma vez que trabalhos acadêmicos, manuais, protocolos, diretrizes e outros documentos estão disponíveis para download e cópia, possibilitando a leitura e o aprofundamento dos estudos. Porém, vale destacar que um dos pontos preocupantes da $\mathrm{EaD}$, no que se refere à busca por informações, é justamente a qualidade desses materiais, o que pode gerar um fluxo de contradições e não equivalência em relação aos conteúdos abordados na prática pedagógica.

Os entrevistados informaram que, para o uso da Internet, possuem dispositivos de comunicação, sendo destacados caixas de som, microfones, webcam e outros. Destes, as webcams foram as mais apontadas $(\mathrm{n}=179)$, o que reforça a finalidade de uso para possibilidade de interação em tempo real.

Perguntados se já ouviram falar em EaD, 189 afirmaram que sim, o que mostra que, atualmente, há uma grande evidência do uso da $\mathrm{EaD}$, em várias esferas da educação. Dos entrevistados, 87 estudantes já realizaram alguma atividade (curso, seminário, palestra, etc.) 
nesta modalidade. Uma das questões apresentadas aos entrevistados visou detectar o tempo em que tais atividades foram realizadas. Verificou-se que foram desenvolvidas em menos de um ano, o que reforça o uso da $\mathrm{EaD}$, na contemporaneidade, como ferramenta de ampliação do conhecimento. Dos entrevistados, 79 ainda informaram que, quando iniciaram as atividades envolvendo $\mathrm{EaD}$, não tinham noção do funcionamento de um curso na modalidade de educação a distância.

O gráfico 3 apresenta dados acerca de como os entrevistados demonstram seu nível de conhecimento em Tecnologias da Informação e Comunicação. Percebe-se que, com o avanço da globalização, o acesso às informações e às tecnologias é acompanhado pela maioria dos estudantes, o que pode facilitar seu engajamento em atividades envolvendo EaD. Ainda, perguntados sobre as bases legais da EaD no Brasil, 87 entrevistados acham que existe uma legislação brasileira que discute e regulamenta a $\mathrm{EaD}$.

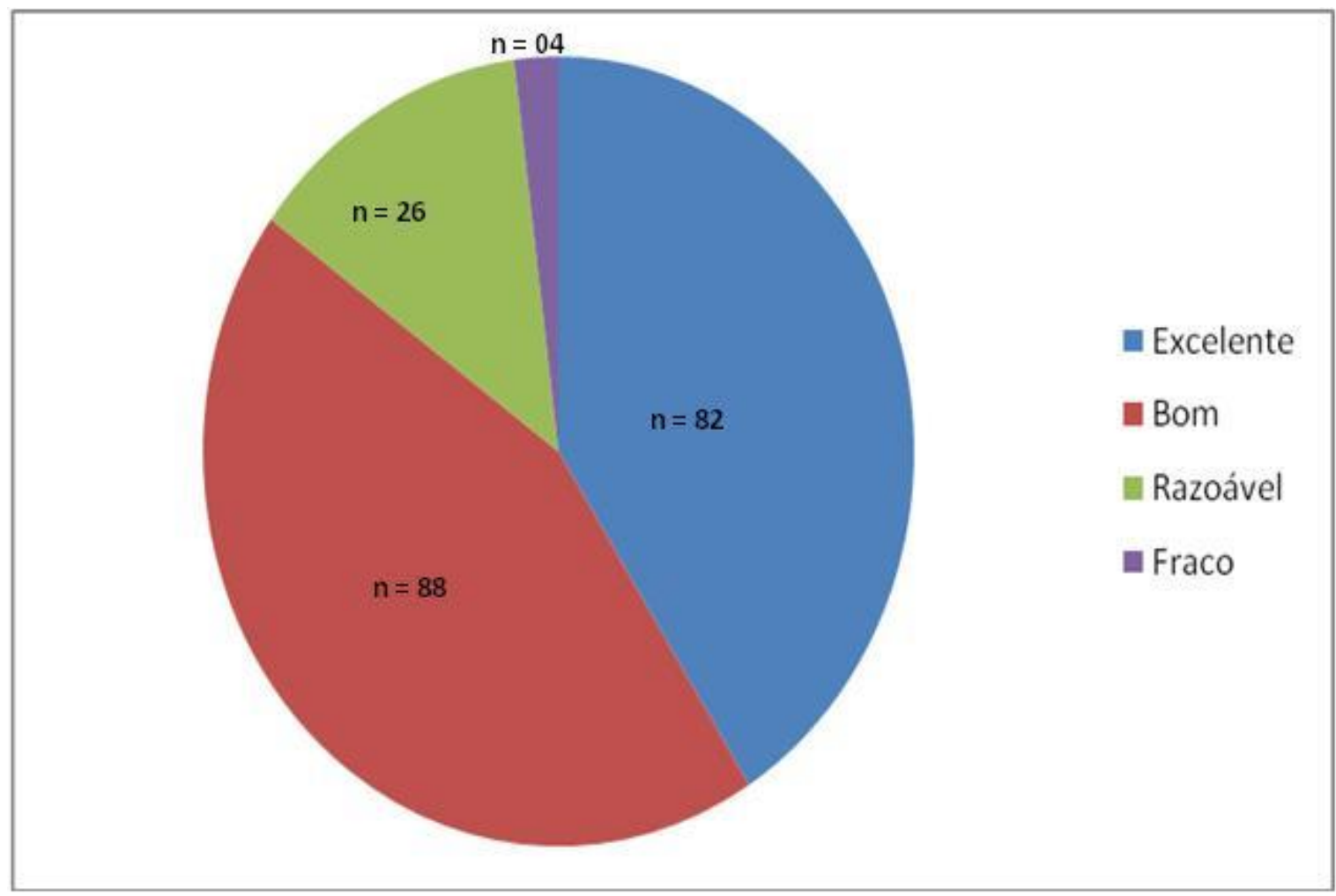

GRÁFICO 3 - Como considera seu nível de conhecimento em Tecnologias da Informação?

O gráfico 4 apresenta as atividades destacadas pelos estudantes que estão relacionadas com a EaD. Chats e blogs foram os mais destacados, o que pode ser relacionado com a real finalidade de uso da Internet pelos entrevistados. Tais aspectos comprovam os dados 
destacados anteriormente em relação ao uso da Internet para promoção da interação em tempo real e webcams.

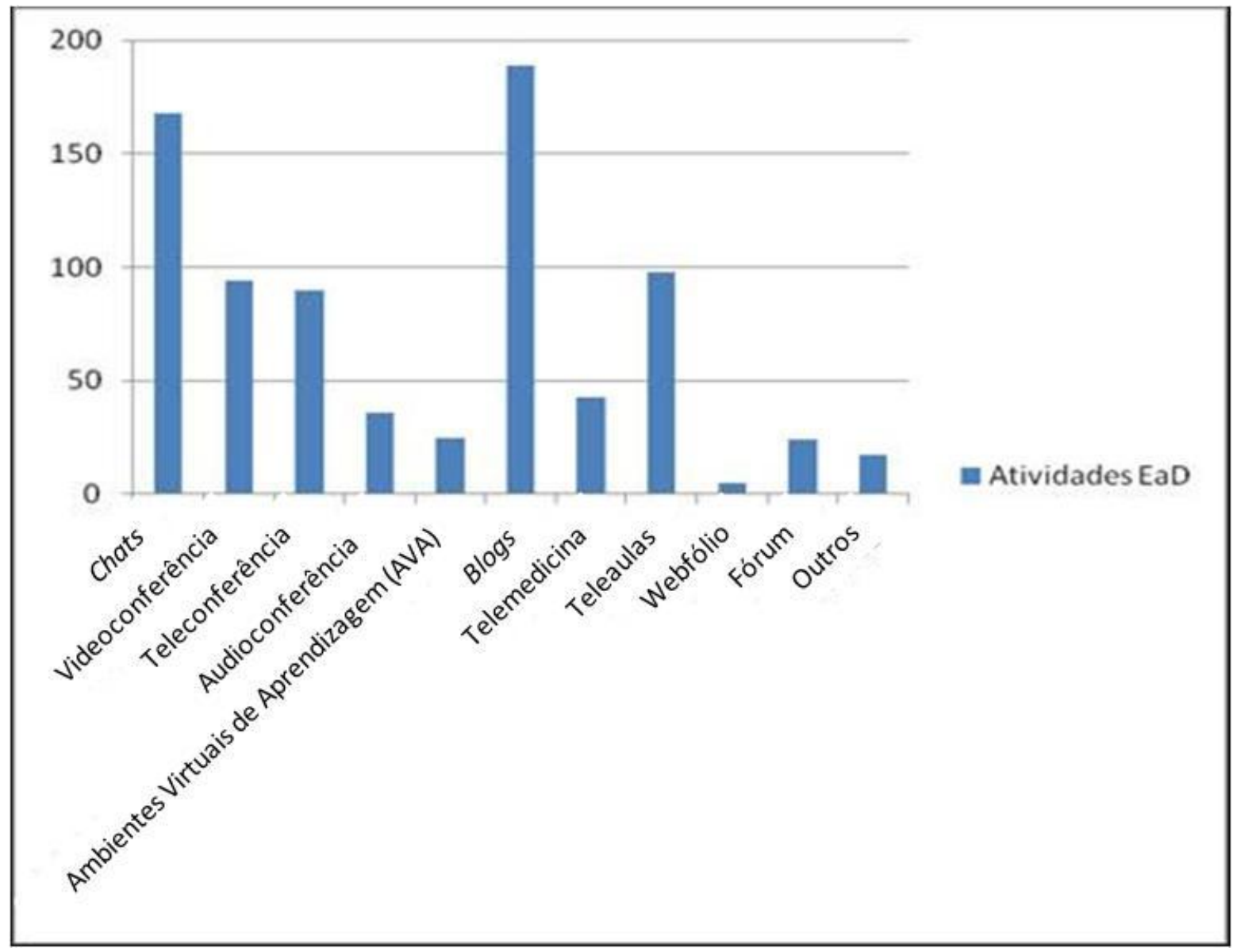

GRÁFICO 4 - De qual destas atividades você já ouviu falar ou utilizou em EaD?

Definidos, no questionário aplicado, os possíveis tipos de interatividade no uso da EaD (passiva: o estudante só recebe informação; ativa assíncrona: o estudante só formula questões, recebendo respostas posteriormente; e ativa síncrona: o estudante e o professor interagem em tempo real), a maioria dos estudantes respondeu $(\mathrm{n}=179)$ que acredita ser passiva a interatividade entre o usuário e o ambiente virtual. Este dado reflete, historicamente e culturalmente, o modelo de prática pedagógica que se faz presente até hoje no Brasil, em que o estudante é apenas um receptor de informações. O gráfico 5 mostra os dados obtidos acerca da interatividade em $\mathrm{EaD}$. 


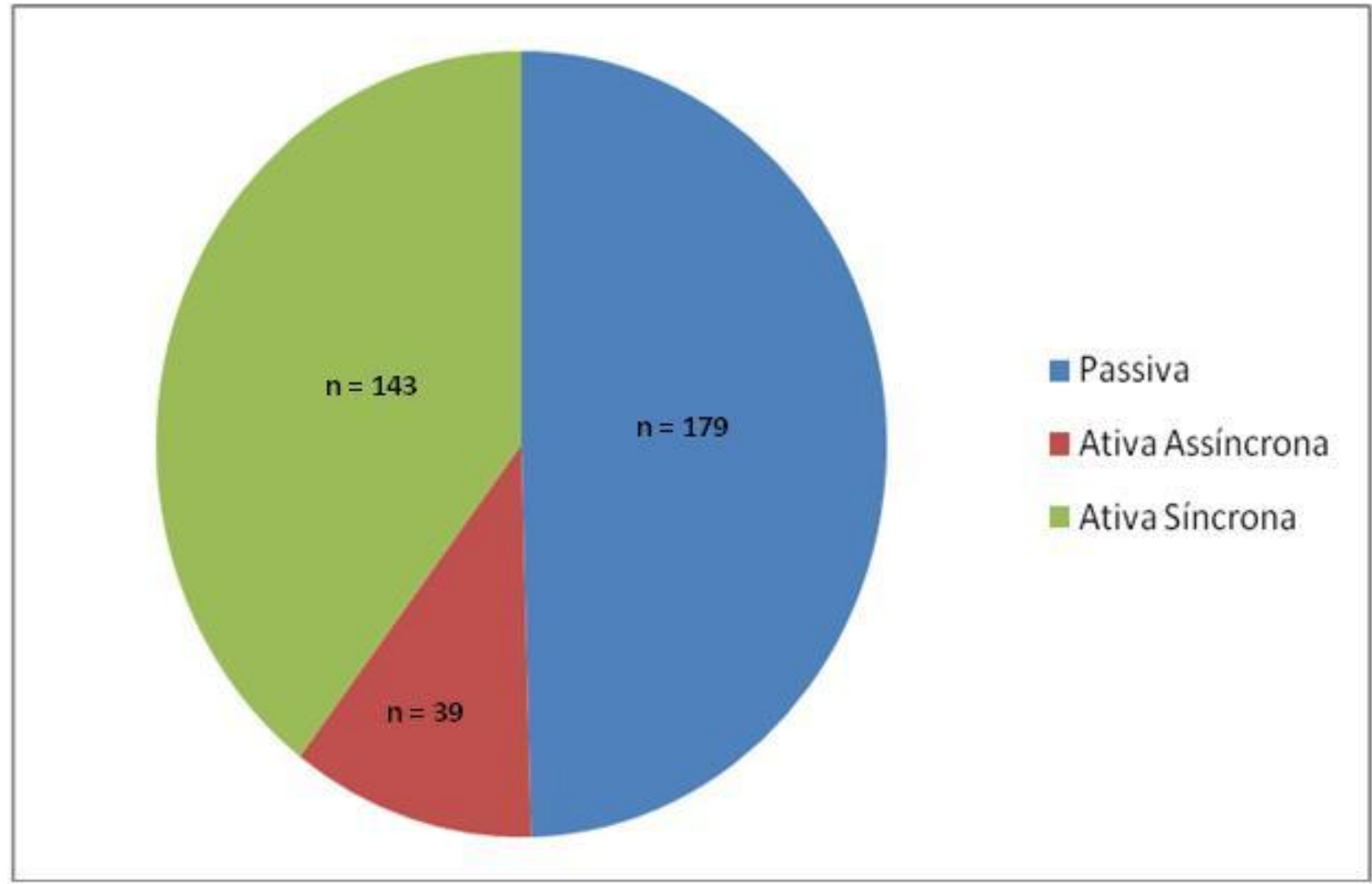

GRÁFICO 5 - Como você classifica a interatividade do estudante com as mídias de suporte para aprendizagem?

Indagados sobre qual o sistema eletrônico (plataforma) de EaD de que já tinham ouvido falar ou que haviam utilizado, 91 estudantes citaram o Moodle como o principal ambiente virtual de aprendizagem. Tal fato se justifica, pois, em duas IES avaliadas, o Moodle já havia sido usado em algumas aulas, de algumas disciplinas, durante as atividades pedagógicas. Apenas três estudantes citaram o e-Proinfo como plataforma conhecida.

No que se refere à avaliação do uso da $\mathrm{EaD}$, de maneira geral, 131 entrevistados afirmaram que há vantagens na $\mathrm{EaD}$, enquanto 69 não visualizaram tais aspectos positivos. Figuram entre os principais atrativos/vantagens da utilização da EaD destacados pelos entrevistados: conveniência de horários, atenção individualizada, cumprimento do curso no prazo prometido e qualidade de materiais didáticos. Dos 87 entrevistados que já realizaram atividades envolvendo $\mathrm{EaD}, 73$ informaram que mudaram seus conceitos anteriores sobre a EaD após iniciar seu curso/atividade; e, dos 200 entrevistados, 139 sentem-se estimulados a realizar um curso a distância. Entre as principais desvantagens citadas pelos entrevistados, destacam-se: exclusão digital (relacionada à necessidade de computadores), número de 
estudantes por tutor, quantidade excessiva de questões de múltipla escolha, não cumprimento das atividades pelos estudantes e evasão.

Dos 200 entrevistados, 132 julgaram ser importante, para os cursos de Ciências Farmacêuticas, a utilização de tecnologias da web como recurso didático ao ensino presencial. Foram destacados os níveis de formação técnica e a atualização na graduação como campos de interesse e necessidade para os entrevistados. O gráfico 6 traz os principais aspectos que levaram os entrevistados a perceber tal necessidade na área em estudo.

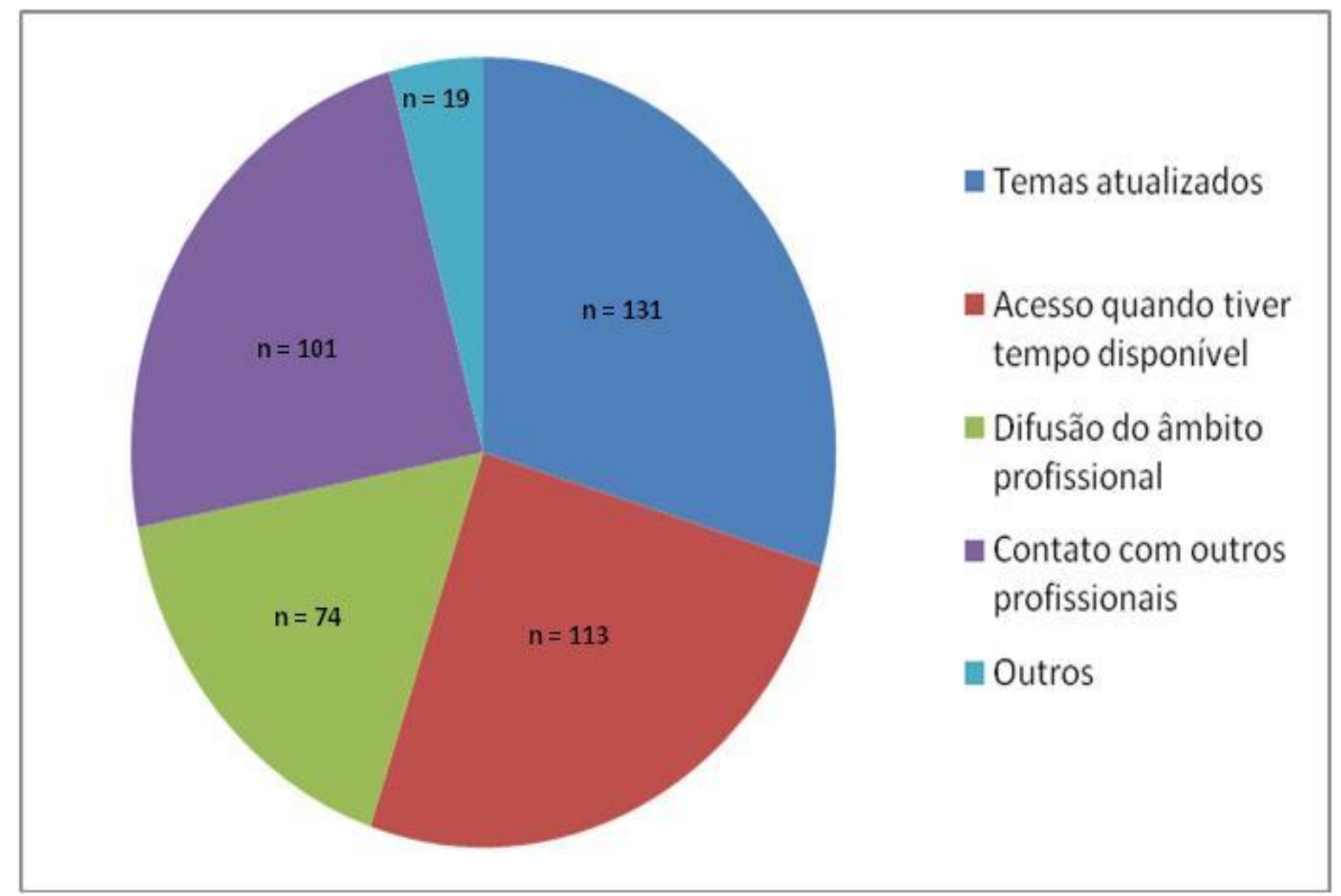

GRÁFICO 6 - Quais as principais vantagens que você identificaria em um curso a distância na área de Farmácia?

Apesar de os entrevistados perceberem a importância da EaD na área das Ciências Farmacêuticas, algumas preocupações/desvantagens foram levadas em conta. Fato pertinente, pois, na área de saúde, é necessário o contato com práticas específicas, tais como estágios e procedimentos técnicos, para maior amplitude e percepção do conhecimento. $\mathrm{O}$ gráfico 7 evidencia os principais pontos de preocupação dos entrevistados com o uso da $\mathrm{EaD}$, na prática das Ciências Farmacêuticas. 


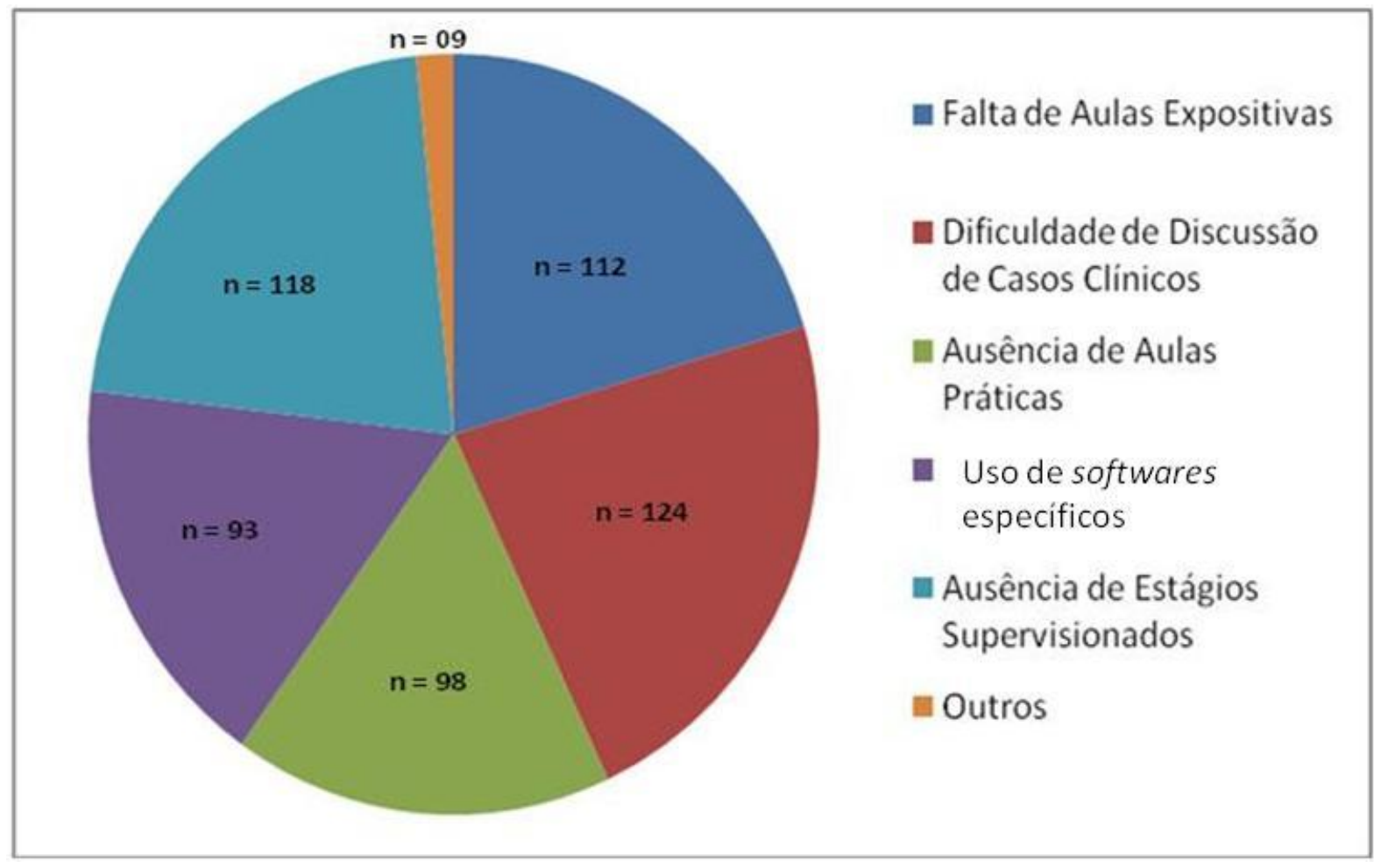

GRÁFICO 7 - Quais as desvantagens/preocupações de um curso a distância na área de Farmácia?

Percebeu-se que, apesar de várias vantagens serem destacadas pelos entrevistados na prática da EaD nas Ciências Farmacêuticas, foram apontadas como fatores mais preocupantes a dificuldade de discussão de casos clínicos e a falta de realização de estágios acadêmicos. Tais indicações mostram uma necessidade do "real" contato com o ser humano (paciente); da verificação de sinais e sintomas; e de uma anamnese completa, o que facilita o diagnóstico e o tratamento.

Indagados sobre as disciplinas que mais se adequavam à prática por $\mathrm{EaD}$, os estudantes destacaram aquelas que possuíam uma abordagem mais teórica, tais como Epidemiologia, Ética e Legislação e Atenção Farmacêutica. Esta observação reflete, mais uma vez, a necessidade de o estudante experienciar a prática da Saúde, complementando seus estudos através de mídias que ampliem sua leitura das disciplinas. 


\section{CONSIDERAÇÕES FINAIS}

A ampla necessidade de aperfeiçoamento do farmacêutico fez com que este buscasse informações em diversas fontes. A partir da Revolução Industrial até a globalização, a obtenção de recursos vem se tornando algo competitivo e acirrado na manutenção da prática profissional. A Internet revolucionou os modos de produção, comercialização e criação de novos produtos farmacêuticos. A expansão das formas de disseminar o conhecimento foi rápida e intensa, cabendo ao profissional farmacêutico consultar fontes de diversas etiologias, inclusive aquelas contidas no mundo virtual.

No meio farmacêutico, também se torna emergente, primeiramente, conhecer as necessidades e as motivações específicas facilitadoras do aprendizado. Essa mudança de paradigma pode também possibilitar a oportunidade para refletir criticamente, experimentar, interagir e colaborar com as inovações na Medicina, antes de adotá-las na prática clínica.

A análise dos dados permitiu perceber que parte dos entrevistados (87 alunos) tinha experiência prévia com a EaD e que 131 alunos entrevistados acreditavam que esta modalidade de ensino poderia ser uma estratégia adequada ao ensino de saúde. Estes destacaram a discussão de temas atualizados, a conveniência de horários e a qualidade de materiais didáticos como pontos favoráveis à inserção da $\mathrm{EaD}$ no ensino das Ciências Farmacêuticas. Por outro lado, apresentaram-se preocupados — principalmente por conta das especificidades de atividades práticas que envolvem farmacêuticos e pacientes — com o nível de qualidade e com a complementaridade dos estudos, dois aspectos que poderiam ser beneficiados por meio de discussão de casos clínicos e da realização de estágios acadêmicos.

Neste contexto, conclui-se que a inserção da $\mathrm{EaD}$ no ensino das Ciências Farmacêuticas é uma estratégia positiva, na opinião dos entrevistados, desde que o planejamento das atividades seja satisfatório para o desenvolvimento adequado das propostas do curso e satisfaça as expectativas dos atores do processo ensino-aprendizagem.

\section{REFERÊNCIAS}

ALVES, Lynn; NOVA, Cristiane. (Org.). Educação a distância: uma nova concepção de aprendizagem e interatividade. São Paulo, SP: Futura, 2003. 
ASSOCIAÇÃO BRASILEIRA DE ENSINO A DISTÂNCIA. In: MACIEL, C. Vantagens e desvantagens da educação à distância no Brasil. 2007. Disponível em: $<$ http://www. artigos.com/artigos/humanas/educacao/vantagens-e-desvantagens-da-educacao-a-distanciano-brasil-1504/artigo/> . Acesso em: 28 maio 2011.

BRASIL. LDBEN. Lei n. 9.394, de 20 de dezembro de 1996. Estabelece as diretrizes e bases da educação nacional. Disponível em: $<$ http://www.planalto.gov.br/CCIVIL_03/ LEIS/L9394.htm>. Acesso em: 28 maio 2011.

BRASIL. MINISTÉRIO DA EDUCAÇÃO (MEC). Decreto n $^{\circ} 5.622$, de 20 de dezembro de 2005 Regulamenta a EAD no Brasil. Disponível em: $<$ http://portal.mec.gov.br/seed/ index.php?option=content\&task=view\&id=61\&Itemid=190>. Acesso em: 28 maio 2011.

CASTRO, P.; NUNES, Ivônio Barros. Centros de teleducação e multimídia. Brasília: Ibase/Fundar, 1996. (Mimeo). Documento proposta de referência apresentado pela Fundação Darcy Ribeiro e pelo Instituto Brasileiro de Análises Sociais e Econômicas ao Ministério do Trabalho, em outubro de 1996.

CHRISTANTE, Luciana. et al. O papel do ensino a distância na educação médica continuada: uma análise crítica. Rev Assoc Med Bras., v. 49, n. 3, p. 326-9, 2003.

ECHEITA, Gerardo; MARTIN, Elena. Interação social e aprendizagem. Porto Alegre: Artes Médicas, 1995.

FAGUNDES, Léa da Cruz. et al. Aprendizagem Cooperativa em Ambientes Telemáticos. Revista Informática na Educação Teoria e Prática, v. 1, n. 2, p. 19-28, 1999.

GOMES, Carmenísia Jacobina Aires; LOPES, Ruth Gonçalves de Faria. Gestão de sistemas de educação a distância: propostade reflexão e prática em ambiente online. In:

CONFERÊNCIA INTERNACIONAL DE EDUCAÇÃO A DISTÂNCIA, 22., Rio de Janeiro, RJ, 2006. Disponível em:

< http://www2.abed.org.br/visualizaDocumento.asp?Documento_ID=53>

Acesso em: 30 maio 2011.

GONDIM, Ana Paula Soares; FALCÃO, Cláudio Borges Falcão. Avaliação das farmácias virtuais brasileiras. Rev Saúde Pública, v. 41, n. 2, p. 297-300, 2007.

GONZALEZ, Marco; POHLMANN FILHO, Omer; BORGES, Karen Selbach. Informação digital no ensino presencial e a distância. Ci. Inf., Brasilia, v. 30, n. 2, p. 101 - 111, maio/ago, 2001.

LEVI, Pierre. A Revolução Contemporânea em Matéria de Comunicação. Trad. Juremir Machado da Silva. Revista FAMECOS, Porto Alegre, n. 9, p. 37-49, dez. 1998.

LITTO, Fredric M. Ead, porque não? O retrato frente/verso da aprendizagem a distância no Brasil. 2009. ETD - Educ. tem. dig., Campinas, v. 10, n. 2, p. 108-122, jun. 2009. 
PÉREZ JUSTE, Ramón. La calidad de la educación universitaria, peculiaridades del modo a distancia. Revista Iberoamericana de Educación a Distancia. Madri, v. 1., p. 151-158, jun.1998.

SOUZA, Marcia Izabel Fugisawa; SILVA, Luciana Oliveira; ARAÚJO, Izabel Cristina. Autoria na web 2.0 no contexto da educação e a ética dos hackers. ETD - Educ. tem. dig., Campinas, v. 12, n. esp., p. 154-173, mar. 2011.

TOMAZ, José Batista Cisne; VAN DER MOLEN, Henk T. Compreendendo os profissionais de saúde da família como potenciais estudantes na educação à distância. Revista Brasileira de Educação Médica, v. 35, n. 2, p. 201-208, 2011.

Como citar este artigo:

SANTOS JÚNIOR, Aníbal de Freitas; BATISTA, Hildonice de Souza. Opinião de estudantes universitários sobre a educação a distância ( $E a D)$, no contexto das ciências farmacêuticas. ETD Educ. temat. digit., Campinas, SP, v.14, n.2, p.258-274, jul./dez. 2012. ISSN 1676-2592. 